\title{
Variation in Uteroglobin-Related Protein 1 (UGRP1) gene is associated with Allergic Rhinitis in Singapore Chinese
}

Anand Kumar Andiappan ${ }^{1 \dagger}$, Wei Sheng $\mathrm{Yeo}^{1 \dagger}$, Pallavi Nilkanth Parate ${ }^{1}$, Ramani Anantharaman ${ }^{1}$, Bani Kaur Suri ${ }^{1}$, De Yun Wang ${ }^{2}$, Fook Tim Chew ${ }^{1 *}$

\begin{abstract}
Background: Uteroglobin-Related Protein 1 (UGRP1) is a secretoglobulin protein which has been suggested to play a role in lung inflammation and allergic diseases. UGRP1 has also been shown to be an important pneumoprotein, with diagnostic potential as a biomarker of lung damage. Previous genetic studies evaluating the association between variations on UGRP1 and allergic phenotypes have yielded mixed results. The aim of this present study was to identify genetic polymorphisms in UGRP1 and investigate if they were associated with asthma and allergic rhinitis in the Singapore Chinese population.
\end{abstract}

Methods: Resequencing of the UGRP1 gene was conducted on 40 randomly selected individuals from Singapore of ethnic Chinese origin. The polymorphisms identified were then tagged and genotyped in a population of 1893 Singapore Chinese individuals. Genetic associations were evaluated in this population comparing 795 individuals with allergic rhinitis, 718 with asthma (of which 337 had both asthma and allergic rhinitis) and 717 healthy controls with no history of allergy or allergic diseases.

Results: By resequencing the UGRP1 gene within our population, we identified 11 novel and 16 known single nucleotide polymorphisms (SNPs). TagSNPs were then genotyped, revealing a significant association between rs7726552 and allergic rhinitis (Odds Ratio: 0.81, 95\% Confidence Interval: 0.66-0.98, P = 0.039). This association remained statistically significant when it was analyzed genotypically or when stratified according to haplotypes. When variations on UGRP1 were evaluated against asthma, no association was observed.

Conclusion: This study documents the association between polymorphisms in UGRP1 and allergic rhinitis, suggesting a potential role in its pathogenesis.

\section{Background}

Allergic diseases such as asthma, allergic rhinitis and atopic dermatitis are global health problems affecting $10-25 \%$ of the world's population. Allergic rhinitis (AR) is an IgE-mediated inflammatory disease of the nasal mucosa which is caused by exposure to allergens. AR is characterized by hyper-responsiveness, high levels of Th2 cells [1] and manifestation of symptoms such as rhinorrhea, sneezing, nasal congestion and rhino-conjunctivitis. AR affects approximately 500 million people

\footnotetext{
* Correspondence: dbscft@nus.edu.sg

+ Contributed equally

'Department of Biological Sciences, National University of Singapore, Science Drive 4, 117543, Singapore

Full list of author information is available at the end of the article
}

worldwide [2,3]. In Singapore, the prevalence of AR was reported to be $13.1 \%$ [4]. AR is not a life threatening disease; however its impact on the quality of life and productivity is significant $[3,5]$. In addition, AR is known to be associated with other conditions such as asthma, sinusitis, anosmia, otitis media, nasal polyps, lower airway infections and dental malocclusion [2,6-8].

Many reports support a genetic basis for atopy and allergy $[9,10]$. The underlying pathogenic mechanism of allergic diseases is not fully elucidated and may be the result of complex interactions between genetic and environmental factors $[2,6]$. Studies looking at twins have provided convincing evidence for a genetic influence, as observed by the greater concordance of allergic

\section{Biomed Central}


manifestations in monozygotic compared to dizygotic twins [11-14]. Non-genetic factors such as an increase in exposure to irritants and allergens, changes in lifestyle, nutrition, pollution and stress, may also influence the onset and development of atopic diseases [7,15-17]. Individuals with a strong family history of allergic disease are more likely to develop allergic symptoms, irrespective of the varying environmental risk factors across societies $[15,18]$.

The gene coding for secretoglobulin (SCGB3A2), also known as UGRP1, is located within chromosome 5q3133. This region of the human chromosome 5 also contains many other candidate genes for allergic diseases such as interleukins - IL-3,IL-4,IL-5,IL-9,IL-13; macrophage colony stimulating factor (CSF) and $\beta_{2}$-adrenergic receptor (ADRB2) [19]. Genetic variations in UGRP1 have been associated with autoimmune diseases such as Hashimoto thyroiditis (HT) and Graves' disease (GD) [20], and allergic diseases such as asthma [21]. A promoter polymorphism in the gene (G-112A) was found to increase the risk of asthma in a Japanese population [19]. However, the association was not replicated in studies involving Indians [22] and German Caucasians [23]. There has not been any association study evaluating the role of these polymorphisms in AR to date. In Singapore a family based linkage study had previously identified the 5q31-33 region to be significantly linked to atopy and asthma in the local ethnic Chinese population [24]. As part of a larger study to fine-map candidate genes for atopy and asthma in this chromosome region, resequencing of the UGRP1 gene was performed, with the aim of identifying novel polymorphisms in Singapore Chinese and evaluating their association to allergic rhinitis and asthma.

\section{Methods}

\section{Ethics Statement}

This study has been performed with the approval of the Institutional Review Board (IRB, Reference - NUS07-023 and NUS10-343) of the National University of Singapore and is in compliance with the Helsinki declaration.

\section{Study Population}

Ethnic Chinese subjects were recruited at the National University of Singapore, KK Women's and Children Hospital and the National University Hospital as a part of an on-going epidemiological collection for the study of allergic diseases and through multiple recruitment drives in Singapore (Table 1). Those not born in Singapore and did not reside locally in the past 10 years were excluded. Volunteers were then classified as individuals with AR, asthma and healthy controls according to their status as determined by an interviewer-administered questionnaire based on the Allergic Rhinitis Impact on
Table 1 Demographic and clinical characteristics of the samples used in the study

\begin{tabular}{llll}
\hline & Asthma $^{\#}$ & Allergic Rhinitis (AR) & Healthy controls \\
\hline Subjects & 718 & 795 & 717 \\
\hline Age, mean & 20.24 & 21.06 & 22 \\
\hline Gender & & & \\
\hline Male & $377(52.5 \%)$ & $385(48.4 \%)$ & $196(27.3 \%)$ \\
\hline Female & $341(47.5 \%)$ & $410(51.6 \%)$ & $521(72.7 \%)$
\end{tabular}

\#an asthma case was classified based on doctor diagnosis of the disease with a positive skin prick test reaction to one of the allergens tested (based on WHO and GINA guidelines for asthma).

\$Allergic Rhinitis (AR) was classified based on 2 or more major symptoms which include (nasal congestion, rhinorrhea, nasal itching, sneezing) and a positive skin prick test reaction to one of the allergens tested (based on 2008 guidelines set by Allergic Rhinitis Impact on Asthma (ARIA) consortium).

${ }^{\wedge}$ Healthy controls are individuals classified based on no symptoms or history of allergic disease and are non- atopic (Negative skin prick test reaction to ALL of the allergens).

Note: All samples have been age-category matched.

Asthma (ARIA) and International Study of Asthma and Allergies in Childhood (ISAAC) guidelines $[2,6]$, and a doctor's diagnosis. The validity and use of ARIA- and ISAAC-based questionnaires has been discussed by others groups [25,26] and ours as well [27]. In addition, all volunteers were subjected to a skin prick test (SPT) using a panel consisting of common allergens in Singapore such as Dermatophagoides pteronyssinus (house dust mite), Blomia tropicalis (dust mite), Elaeis guineensis (pollen) and Curvularia lunata (fungi). A SPT response is considered positive when the wheal diameter is $3 \mathrm{~mm}$ or greater, when compared to positive (histamine) and negative (saline) controls. The selection of these allergens was based on previous studies in the region which clearly demonstrated that sensitization of the major indoor allergen - the house dust mite (HDM), was considered an important risk factor for the development of asthma and allergic diseases, especially in South East Asian populations, such as those from Singapore, Malaysia and Thailand [28-30]. Based on our previous epidemiological studies [31,32], the majority of AR and atopic asthma individuals would be sensitized to one or both of the major dust mites evaluated (Dermatophagoides pteronyssinus, and/or Blomia tropicalis) and up to $30 \%$ would be poly-sensitized (to dust mites and pollen and/or fungal allergens). Atopy was defined as a positive SPT response to either dust mite allergen extracts, with or without poly-sensitization to other allergens. AR was diagnosed based on the presence of the atopic status and typical AR symptoms as defined by the ARIA 2008 guidelines [2,6], i.e., two or more AR symptoms (nasal congestion, rhinorrhea, nasal itching, sneezing) persisting for four or more days a week during the past year. Asthma was classified based on a positive doctor-diagnosed asthma with wheezing symptoms and positive skin prick responses to 
common allergens. A subset of the asthmatic individuals would have complete ACT (Asthma Control Test) scores, lung function and peak flow reversibility data. (This is however currently on-going, and thus not reported in this study). Conversely, healthy control individuals were defined as those with no atopy (i.e., skin prick negative) and with no history of allergic conditions, diagnosis, or symptoms.

\section{Resequencing}

Genomic DNA was extracted from buccal cells obtained from $15 \mathrm{ml}$ of mouthwash in $0.9 \%$ saline solution as previously described [33]. DNA was then quantified using Nanodrop and by flourimetric analysis using PicoGreen (Molecular Probes, Invitrogen, OR, USA). DNA from a subset of 40 randomly selected individuals was used for sequencing and the identification of genetic polymorphisms [34]. The 3 exons and exon-intron boundaries of UGRP1 were sequenced (Additional File 1). Information on primer sequences and the regions covered by resequencing have been described below in Additional File 2.

\section{Genotyping}

Genotyping was performed on the Illumina BeadXpress platform (Illumina Inc., San Diego, CA, USA) at the University of Utah Genomics Core Facility (Salt Lake City, UT, USA) according to manufacturer's recommendations.

\section{Statistical Analysis}

Linkage Disequilibrium (LD) blocks were generated with the SNPs identified using Haploview v4.2 [26]. HardyWeinberg equilibrium (HWE) was assessed in the control population as a quality control measure. Tests for association were performed at the allelic, genotypic and haplotypic levels and odds ratio with 95\% confidence intervals were estimated by PLINK v1.06. A $P$-value less than 0.05 were considered statistically significant (with Bonferroni corrections for multiple testing where necessary).

\section{In silico analysis using bioinformatics tools}

In silico analysis was performed using bioinformatics tools such as TRANSFAC, http://www.gene-regulation. com/cgi-bin/pub/databases/transfac/search.cgi and TFSEARCH http://www.cbrc.jp/research/db/TFSEARCH. html to predict potential transcription factor binding site (TFBS) and possible effects of the polymorphisms on the binding of transcription factors. The results were cross compared using another transcription factor prediction server, ALIBABA v2.1 http://www.gene-regulation.com/ pub/programs/alibaba2/index.html.

\section{Results}

\section{Resequencing}

Of the 27 polymorphisms identified through resequencing of the UGRP1 gene [23 SNPs and 4 INDELs (INsertion/DELetion)], 11 were novel (Additional File 3). Of the 16 polymorphisms previously reported in NCBI, only 4 SNPs were present in the HapMap database for the Han Chinese (CHB) population. LD blocks were constructed using $\mathrm{r}^{2}$ values estimated for all SNPs identified through the resequencing of the UGRP1 gene (Figure 1). Tagging was performed using an LD threshold of $\mathrm{r}^{2}=0.8$ resulting in a total of 11 tagSNPs representing the variations in UGRP1 among Singapore Chinese. (Additional File 4)

\section{Single SNP marker association analysis}

A total of 10 out of the 11 tag SNPs in UGRP1 (Figure 2), targeted for genotyping, passed the BeadXpress assay design quality control and were successfully genotyped in 1893 samples (with a genotyping success rate of 99.6\%). Allele based association analyzed using the Cochran Armitage trend test for the AR phenotype revealed that rs7726552 is significantly associated $\left(P_{\text {trend }}=0.032\right.$, $\mathrm{OR}=0.81)$ (Table 2). Association at the genotype level appeared stronger with $P_{\text {genotype }}=0.00085$ and $\mathrm{OR}=0.79$ $\left(P_{\text {Bonferroni }}=0.0085\right)($ Table 3$)$. No significant association was detected for the asthma phenotype (Additional File 5).

\section{Haplotype based association analysis}

Haplotypes within UGRP1 were tested for significant associations with the atopic conditions using PLINK. The haplotype H2 (ATGGTGC), covering a region of $4.13 \mathrm{~kb}$, encompassing the promoter and the first intron, and consisted of the SNPs rs7726552, rs7727031, UGRP1-G-1351A, rs6882292, rs17107353, rs17703574 and UGRP1-C1360A, was found to be the most common with a frequency of $69.6 \%$ in controls and $65.5 \%$ in cases $(P=0.017)$ (Table 4). These results are consistent with the single SNP association of rs7726552 with AR, and where the allele frequencies were $14 \%$ in cases and $17 \%$ in controls $(\mathrm{P}=0.039)$.

\section{In silico prediction of putative function}

TRANSFAC was used to predict possible TFBS which might be affected due to the SNP. The in silico prediction tool revealed that the region containing SNP rs7726552 has potential consensus binding sites for transcription factors Oct-1, NF-1 and GATA-1. The A to T polymorphism was predicted to result in a new binding site for GATA-1, the loss of binding site for Oct-1 and no change in transcription factor binding for NF-1. Similar results were also shown using TFBS software ALIBABA 2.1. 


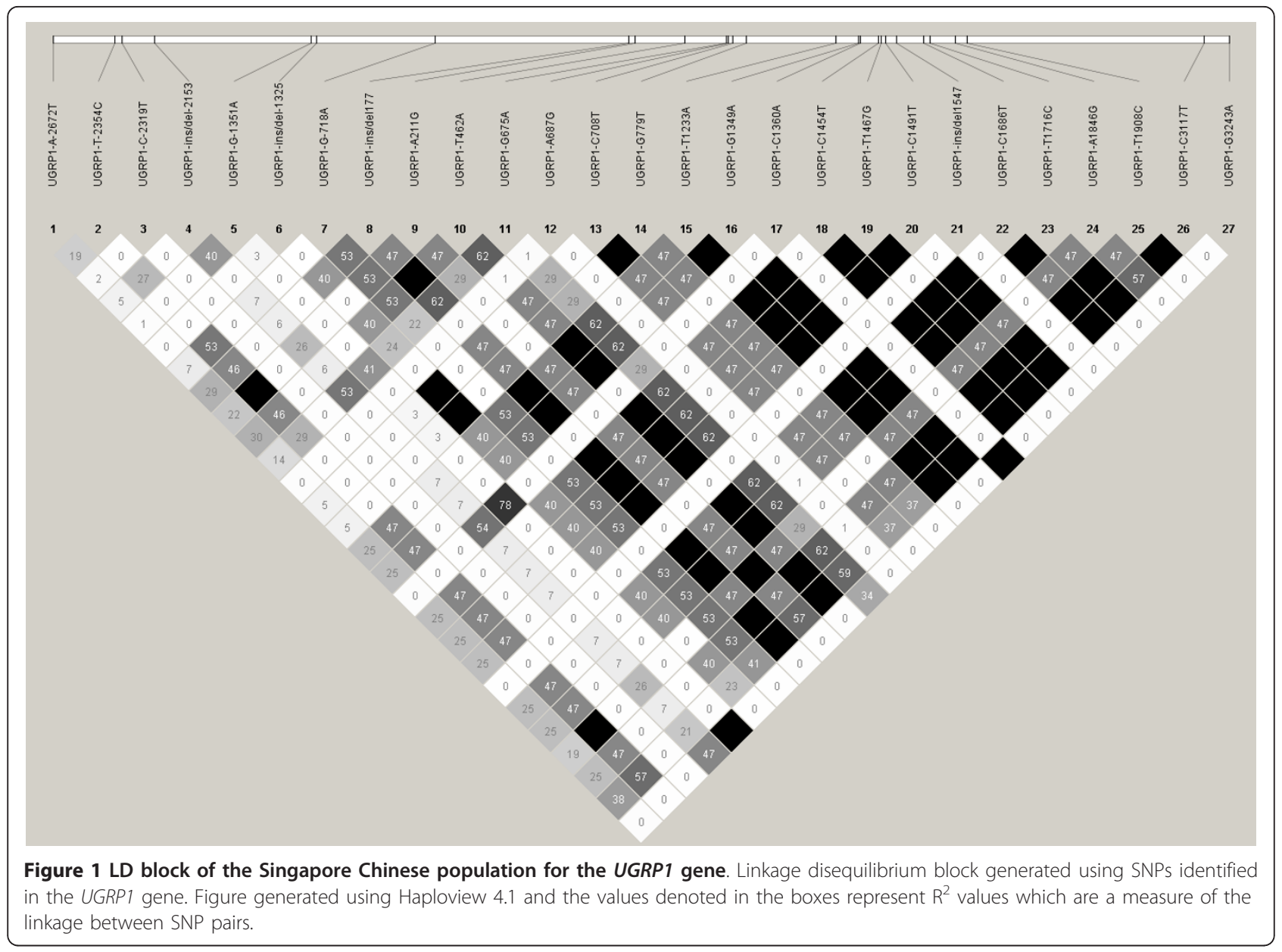

\section{Discussion}

UGRP1 was originally suggested to have an anti-inflammatory function due to its similarity to uteroglobin/ Clara cell secretory protein [21]. UGRP1 is localized in the chromosome 5q31-32 region where asthma susceptibility locus has been assigned [35] and the high expression of this protein in epithelial cells of the airway [21] suggests a possible role in allergic airway inflammation. Further evidence of the role of UGRP1 is seen in its regulation by various T-regulatory cytokines such as IL-10 [36], IL-5 and IL-9 [37,38], suggesting its involvement in allergic response. Claire et al., have shown that there is an increase in UGRP1 in the induced sputum of patients with asthma and rhinitis, further suggesting a possible role in inflammatory diseases [39].

The SNP rs7726552 showed significant association with AR in our population. Haplotype analysis revealed a single haplotype block which, when tested for association, was significantly different in cases as compared to controls. This haplotype block, a $4.13 \mathrm{~kb}$ region, includes the 5 ' upstream, promoter and the first intron. The SNP rs7726552 is present in the 5' upstream region

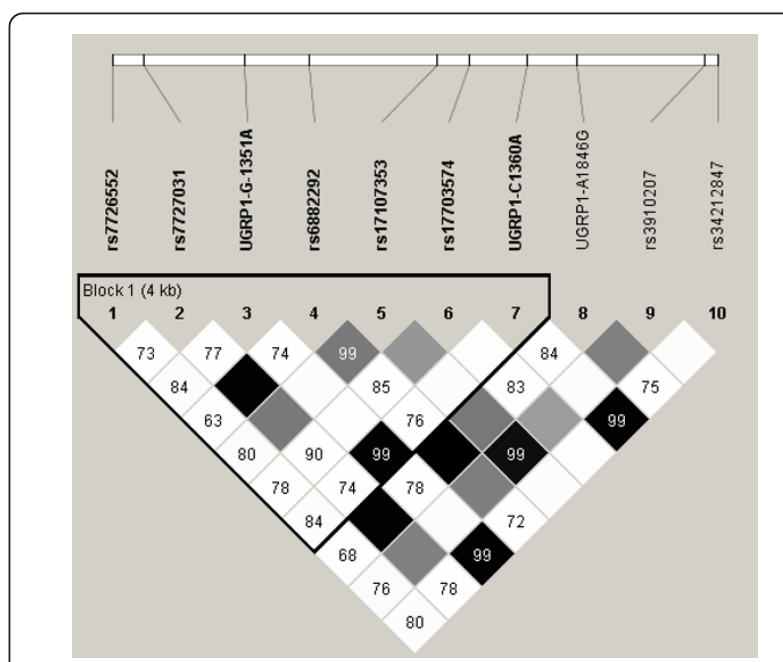

Figure 2 LD block generated using tagSNPs genotyped for the UGRP1 gene. Linkage disequilibrium block generated using tagSNPs genotyped for the entire study population. Figure generated using Haploview 4.1 and the values denoted in the boxes represent $R^{2}$ values which are a measure of the linkage between SNP pairs. 
Table 2 Allele based association test for Allergic Rhinitis (AR) phenotype

\begin{tabular}{|c|c|c|c|c|c|c|c|c|c|}
\hline \multirow[t]{2}{*}{ SNP } & \multirow[t]{2}{*}{ Position } & \multirow[t]{2}{*}{$\begin{array}{l}\text { Minor } \\
\text { allele }\end{array}$} & \multicolumn{2}{|c|}{$\begin{array}{c}\text { Allele } \\
\text { Frequency }\end{array}$} & \multirow[t]{2}{*}{$\begin{array}{l}\text { Major } \\
\text { Allele }\end{array}$} & \multirow[t]{2}{*}{$P_{\text {trend }}$} & \multirow[t]{2}{*}{ OR } & \multirow[t]{2}{*}{ L95 } & \multirow[t]{2}{*}{ U95 } \\
\hline & & & Cases & Controls & & & & & \\
\hline rs7726552 & 147235795 & $\mathrm{~T}$ & 0.14 & 0.17 & A & $0.039^{*}$ & 0.81 & 0.66 & 0.98 \\
\hline rs7727031 & 147236113 & C & 0.06 & 0.06 & $\mathrm{~T}$ & 0.544 & 0.91 & 0.67 & 1.23 \\
\hline UGRP1-G-1351A & 147237116 & A & 0.07 & 0.07 & G & 0.641 & 1.07 & 0.81 & 1.41 \\
\hline rs6882292 & 147237749 & A & 0.06 & 0.06 & G & 0.739 & 0.95 & 0.70 & 1.28 \\
\hline rs17107353 & 147239022 & $A$ & 0.11 & 0.12 & $\mathrm{~T}$ & 0.154 & 0.85 & 0.67 & 1.06 \\
\hline rs17703574 & 147239339 & $T$ & 0.05 & 0.06 & $G$ & 0.141 & 0.79 & 0.56 & 1.08 \\
\hline UGRP1-C1360A & 147239920 & $A$ & 0.07 & 0.07 & $C$ & 0.81 & 1.04 & 0.78 & 1.36 \\
\hline UGRP1-A1846G & 147240405 & G & 0.06 & 0.06 & A & 0.687 & 0.94 & 0.69 & 1.27 \\
\hline rs3910207 & 147241677 & $T$ & 0.11 & 0.13 & $C$ & 0.202 & 0.87 & 0.69 & 1.08 \\
\hline rs34212847 & 147241803 & A & 0.07 & 0.07 & G & 0.668 & 1.06 & 0.80 & 1.4 \\
\hline
\end{tabular}

$\mathrm{P}_{\text {trend }}$ is calculated by the Cochran Armitage trend test using the PLINK $v 1.06$ software.

${ }^{*} P_{\text {trend }}<0.05$ for the association test for AR.

$\mathrm{OR}$ - Odds ratio; $\mathrm{Cl}$ - Confidence Interval.

and hence could affect the regulation of gene expression levels. Previous reports have shown that such polymorphisms in the UGRP1 gene could predispose an individual to allergic inflammation by reducing the levels of UGRP1 in the airway epithelial cells [19]. Interestingly, the promoter polymorphism G-122A, which was previously associated with asthma in Japanese people [19] was also identified in our population and was designated as UGRP1-G-1351A. However, similar to studies on Indians and German Caucasians, the association to asthma for this SNP was not replicated in the Singapore Chinese population. This could be attributed to underlying differences in the genetic makeup of the populations evaluated. The evaluation of the influence of rs7726552 on UGRP1 expression and regulation would be helpful in identifying the role it may play in allergy. Much is known as to how a gene is regulated and this may involve multiple potential mechanisms such as differential gene splicing or binding of transcription factors to regulatory elements. The presence of SNPs in these regulatory regions might then predispose an individual to disease $[40,41]$. The in silico analysis revealed potential binding sites for Oct-1, NF-1 and GATA-1 at the 5' upstream locus where rs7726552 was identified. Oct-1 has been previously shown to be important in regulating the expression of IL13 which is a key regulator of Th2mediated inflammation in allergic diseases. Kiesler et al., demonstrated that a polymorphism in the regulatory element affects the transcription of the IL13 gene by creating a binding site for Oct-1 [42]. Similarly, Hasegawa et al., demonstrated that the $\mathrm{T}$ allele on the Fc epsilon RI alpha-chain promoter introduced an additional binding motif for GATA-1 compared to the C allele and hence the transcription activity of the $\mathrm{T}$ allele was enhanced because of the higher affinity for the transcription factor [43]. In a similar fashion, the A to $\mathrm{T}$ change in rs7726552 is predicted to result in the loss of the binding site for Oct- 1 and conversely introduce an additional binding site for GATA-1. This prediction suggests why the $\mathrm{T}$ allele confers protection (OR 0.81) with a higher proportion of the controls (17\%) having the allele as compared to the cases (14\%). The genotyping

Table 3 Genotype based association test for Allergic Rhinitis (AR) phenotype

\begin{tabular}{|c|c|c|c|c|c|c|c|c|}
\hline SNP id & $\begin{array}{l}\text { Minor } \\
\text { Allele }\end{array}$ & $\begin{array}{l}\text { Major } \\
\text { Allele }\end{array}$ & Model & Genotype & Case (\%) & Control (\%) & $\chi^{2}$ & $\mathrm{P}$ \\
\hline \multirow[t]{5}{*}{ rs7726552 } & $\mathrm{T}$ & A & Full genotype & $\pi$ & $16(2.02)$ & $6(0.84)$ & & \\
\hline & & & & TA & $190(23.93)$ & $227(31.70)$ & & \\
\hline & & & & AA & $588(74.06)$ & $483(67.46)$ & 7.95 & $0.00085^{*}$ \\
\hline & & & Dominant & $\mathrm{TT}+\mathrm{TA}$ & 206 (25.94) & $233(32.54)$ & & \\
\hline & & & & AA & $588(74.06)$ & $483(67.46)$ & 14.13 & $0.0048^{\#}$ \\
\hline
\end{tabular}

*P value calculated using $\chi^{2}$ test of association for all the three genotypes.

\#P value calculated using $\chi^{2}$ test of association for a dominant model. 
Table 4 Association of AR associated haplotypes in UGRP1 gene

\begin{tabular}{|c|c|c|c|c|c|c|c|c|c|c|}
\hline \multirow[t]{2}{*}{ Haplotype } & \multirow[t]{2}{*}{ rs7726552 } & \multirow[t]{2}{*}{ rs7727031 } & \multirow{2}{*}{$\begin{array}{c}\text { UGRP1-G- } \\
1351 \mathrm{~A}\end{array}$} & \multirow[t]{2}{*}{ rs6882292 } & \multirow[t]{2}{*}{ rs17107353 } & \multirow[t]{2}{*}{ rs 17703574} & \multirow{2}{*}{$\begin{array}{l}\text { UGRP1- } \\
\text { C1360A }\end{array}$} & \multicolumn{2}{|c|}{ Haplotype frequency } & \multirow[t]{2}{*}{ P value* } \\
\hline & & & & & & & & $\begin{array}{c}717 \\
\text { controls }\end{array}$ & $\begin{array}{l}795 \\
\text { cases }\end{array}$ & \\
\hline $\mathrm{H} 1$ & A & C & G & A & A & G & C & 0.053 & 0.059 & 0.536 \\
\hline $\mathrm{H} 2$ & A & $\mathrm{T}$ & G & G & $\mathrm{T}$ & G & C & 0.696 & 0.655 & 0.017 \\
\hline $\mathrm{H} 3$ & A & $\mathrm{T}$ & A & G & T & G & A & 0.071 & 0.066 & 0.637 \\
\hline $\mathrm{H} 4$ & $\mathrm{~T}$ & $\mathrm{~T}$ & G & G & $\mathrm{T}$ & G & C & 0.135 & 0.162 & 0.036 \\
\hline H5 & A & $\mathrm{T}$ & G & G & $A$ & $\mathrm{~T}$ & C & 0.046 & 0.058 & 0.120 \\
\hline
\end{tabular}

Haplotypes are constructed using the sliding window method by PLINK software. Haplotype frequencies are estimated using the Haploview software.

*P value calculated using $\chi^{2}$ test of association for haplotypes.

results showed more evidence for a dominant model of association producing a $\mathrm{P}_{\text {dominant }}=0.0048$ and $\mathrm{OR}=$ 0.79 . The functional significance and the mechanism of the causal variant in UGRP1 leading to the onset of allergic rhinitis needs to be confirmed and validated with further studies.

Haplotype association analysis revealed a common haplotype on UGRP1 to have significant different frequencies between cases and controls. This haplotype block contains 7 SNPs from the promoter region and first intron. Previous reports on the UGRP1 gene have also confirmed the functionality of haplotype to be associated to the promoter region [36] and the regulation of UGRP1 expression in asthmatic patients [19]. Srisodsai et al., have shown that in a mouse model, administration of IL10 increased constitutive UGRP1 mRNA expression and suggested UGRP1 as a potential target for IL-10 anti-inflammatory activities in the lung [36]. Chiba et al., demonstrated that UGRP1 can suppress inflammation in a mouse model for allergic airway inflammation and also proposed UGRP1 as a therapeutic candidate for treating lung inflammation [35]. These reports highlight a potential role for UGRP1 in treatment of allergic airway diseases.

\section{Conclusion}

In summary, our study reveals the association of UGRP1 polymorphisms, specifically rs7726552, with allergic rhinitis in the Singapore Chinese population. Haplotype analysis suggests that multiple polymorphisms in the gene could be contributing collectively to the pathogenesis of AR. Further functional characterization of these variants would be important in determining if these variants could be used as risk factors for AR.

\section{Additional material}

Additional file 1: Gene structure of UGRP1. Figure describing the structure of the UGRP1 gene on chromosome 5.
Additional file 2: Primers used for sequencing UGRP1 gene. The list of primers used for sequencing of the UGRP1 gene.

Additional file 3: Summary of polymorphisms identified through sequencing of UGRP1 gene. Table summarizing the total polymorphisms identified by sequencing the UGRP1 gene.

Additional file 4: TagSNPs chosen for genotyping for case control association. The list of SNPs selected for genotyping of the UGRP1 using the tagging approach.

Additional file 5: Association of UGRP1 SNPs to Asthma phenotype (Allele based test). Table summarizing the Association of the UGRP1 SNPs calculated using the allele based test for the asthma phenotype.

\section{Acknowledgements}

We are thankful to Dr. Stuart Morgan and Mr Rueben Sng for their assistance in reviewing the manuscript.

Financial Support

This study has been funded by grants from the Singapore Immunology grant Network (SlgN-06-006 and SlgN-08-020), Biomedical Research Council (BMRC), Singapore National Medical Research Council (NMRC), and the National University of Singapore (NUS).

\section{Author details}

'Department of Biological Sciences, National University of Singapore, Science Drive 4, 117543, Singapore. ${ }^{2}$ Department of Otolaryngology, National University of Singapore, 10 Lower Kent Ridge Road, 119260, Singapore.

\section{Authors' contributions}

AKA, WSY, RA, PNP and BKS were involved in the design of the study, recruitment of participants for the study, and extraction of DNA samples. AKA, WSY performed the statistical analysis and drafted the manuscript. PNP performed the resequencing. DYW edited the manuscript. FTC conceived designed and planned the study, as well as edited the manuscript. All authors have read and approved the final manuscript.

\section{Competing interests}

The authors declare that they have no competing interests.

Received: 22 September 2010 Accepted: 16 March 2011 Published: 16 March 2011

\section{References}

1. Kay AB: Advances in immunology - Allergy and allergic diseases - First of two parts. New England Journal of Medicine 2001, 344(1):30-37.

2. Bousquet J, Khaltaev N, Cruz AA, Denburg J, Fokkens WJ, Togias A, Zuberbier T, Baena-Cagnani CE, Canonica GW, van Weel C, et al: Allergic rhinitis and its impact on asthma (ARIA) 2008 update (in collaboration with the World Health Organization, GA(2)LEN and AllerGen). Allergy 2008, 63:8. 
3. Nathan RA: The burden of allergic rhinitis. Allergy Asthma Proc 2007, 28(1):3-9.

4. Ng TP, Tan WC: Epidemiology of allergic rhinitis and its associated riskfactors in singapore. International Journal of Epidemiology 1994, 23(3):553-558.

5. Reed SD, Lee TA, McCrory DC: The economic burden of allergic rhinitis A critical evaluation of the literature. Pharmacoeconomics 2004, 22(6):345-361.

6. Bousquet J, van Cauwenberge P, Khaltaev N, Ait-Khaled N, AnnesiMaesano I, Baena-Cagnani C, Bateman E, Bonini S, Canonica GW, Carlsen $\mathrm{KH}$, et al: Allergic rhinitis and its impact on asthma. J Allergy Clin Immunol 2001, 108(5):S147-S334.

7. Falade $\mathrm{AG}$, Ige $\mathrm{OM}$, Yusuf $\mathrm{BO}$, Onadeko $\mathrm{MO}$, Onadeko BO: Trends in the Prevalence and Severity of Symptoms of Asthma, Allergic Rhinoconjunctivitis, and Atopic Eczema. J Natl Med Assoc 2009, 101(5):414-418.

8. Mosges R, Klimek L: Today's allergic rhinitis patients are different: new factors that may play a role. Allergy 2007, 62(9):969-975.

9. Blumenthal MN: The role of genetics in the development of asthma and atopy. Curr Opin Allergy Clin Immunol 2005, 5(2):141-145.

10. Hurme M, Pessi T, Karjalainen J: Genetics of inflammation and atopy. Ann Med 2003, 35(4):256-258.

11. Bazaral M, Orgel HA, Hamburge Rn: Genetics of ige and allergy - serum ige levels in twins. J Allergy Clin Immunol 1974, 54(5):288-304.

12. Clarke JR, Jenkins MA, Hopper JL, Carlin JB, Mayne C, Clayton DG, Dalton MF, Holst DP, Robertson CF: Evidence for genetic associations between asthma, atopy, and bronchial hyperresponsiveness - A study of 8-to 18-yr-old twins. Am J Respir Crit Care Med 2000, 162(6):2188-2193.

13. Duffy DL, Mitchell CA, Martin NG: Genetic and environmental risk factors for asthma - A cotwin-control study. Am J Respir Crit Care Med 1998, 157(3):840-845.

14. Kim JS, Ouyang FX, Pongracic JA, Fang YP, Wang BY, Liu X, Xing HX, Caruso D, Zhang SC, Xu X, et al: Dissociation between the prevalence of atopy and allergic disease in rural China among children and adults. J Allergy Clin Immunol 2008, 122(5):929-935.

15. Maksimovic N, Tomic-Spiric V, Jankovic S, Jovic-Vranes A, Terzic-Supic Z, Jankovic J: Risk factors of allergic rhinitis: a case-control study. HealthMED 2010, 4(1):63-70

16. Sih T, Mion O: Allergic rhinitis in the child and associated comorbidities. Pediatr Allergy Immunol 2010, 21(1):E107-E113.

17. Bousquet J, Annesi-Maesano I, Carat F, Leger D, Rugina M, Pribil C, El Hasnaoui A, Chanal I: Characteristics of intermittent and persistent allergic rhinitis: DREAMS study group. Clin Exp Allergy 2005, 35(6):728-732.

18. Choi SH, Yoo Y, Yu J, Rhee CS, Min YG, Koh YY: Bronchial hyperresponsiveness in young children with allergic rhinitis and its risk factors. Allergy 2007, 62(9):1051-1056.

19. Niimi T, Munakata M, Keck-Waggoner CL, Popescu NC, Levitt RC, Hisada M, Kimura S: A polymorphism in the human UGRP1 gene promoter that regulates transcription is associated with an increased risk of asthma. American Journal of Human Genetics 2002, 70(3):718-725.

20. Yu Y, Sun LL, Jin Y, Li YS, Shan ZY, Huang W, Teng WP: Association study between the IL4, IL13, IRF1 and UGRP1 genes in chromosomal 5 q31 region and Chinese Graves' disease. J Hum Genet 2005, 50(11):574-582.

21. Niimi T, Keck-Waggoner CL, Popescu NC, Zhou YH, Levitt RC, Kimura S: UGRP1, a uteroglobin/clara cell secretory protein-related protein, is a novel lung-enriched downstream target gene for the T/EBP/NKX2.1 homeodomain transcription factor. Molecular Endocrinology 2001, 15(11):2021-2036.

22. Batra J, Niphadkar PV, Sharma SK, Ghosh B: Uteroglobin-related protein 1 (UGRP1) gene polymorphisms and atopic asthma in the Indian population. International Archives of Allergy and Immunology 2005, 136(1):1-6

23. Heinzmann A, Dietrich H, Deichmann KA: Association of uteroglobulinrelated protein 1 with bronchial asthma. International Archives of Allergy and Immunology 2003, 131(4):291-295.

24. Shek LPC, Tay AHN, Chew FT, Goh DLM, Lee BW: Genetic susceptibility to asthma and atopy among Chinese in Singapore - linkage to markers on chromosome 5q31-33. Allergy 2001, 56(8):749-753.
25. Jenkins MA, Clarke JR, Carlin JB, Robertson CF, Hopper JL, Dalton MF, Holst DP, Choi K, Giles GG: Validation of questionnaire and bronchial hyperresponsiveness against respiratory physician assessment in the diagnosis of asthma. Int J Epidemiol 1996, 25(3):609-616.

26. Lukrafka JL, Fuchs SC, Moreira LB, Picon RV, Fischer GB, Fuchs FD: Performance of the ISAAC Questionnaire to Establish the Prevalence of Asthma in Adolescents: A Population-Based Study. J Asthma 2010, 47(2):166-169.

27. Goh DYT, Chew FT, Quek SC, Lee BW: Prevalence and severity of asthma, rhinitis, and eczema in Singapore schoolchildren. Arch Dis Child 1996, 74(2):131-135.

28. Sporik R, Chapman MD, Plattsmills TAE: House dust mite exposure as a cause of asthma. Clin Exp Allergy 1992, 22(10):897-906.

29. Yeoh SM, Kuo IC, Wang DY, Liam CK, Sam CK, De Bruyne JA, Lee BW, Cheong N, Chua KY: Sensitization profiles of Malaysian and Singaporean subjects to allergens from Dermatophagoides pteronyssinus and Blomia tropicalis. Int Arch Allergy Immunol 2003, 132(3):215-220.

30. Daengsuwan $T$, Lee BW, Visitsuntorn N, Charoenratanakul $S$, Ruangrak $S$, Jirapongsananuruk $\mathrm{O}$, Vichyanond $\mathrm{P}$ : Allergen sensitization to aeroallergens including Blomia tropicalis among adults and childhood asthamatics in Thailand. Asian Pac J Allergy Immunol 2003, 21(4):199-204.

31. Chew FT, Lim SH, Goh DYT, Lee BW: Sensitization to local dust-mite fauna in Singapore. Allergy 1999, 54(11):1150-1159.

32. Chew FT, Lim SH, Shang HS, Dahlia MDS, Goh DYT, Lee BW, Tan HTW, Tan TK: Evaluation of the allergenicity of tropical pollen and airborne spores in Singapore. Allergy 2000, 55(4):340-347.

33. Andiappan AK, Anantharaman R, Parate P, Wang DY, Chew FT: Evaluating the transferability of Hapmap SNPs to a Singapore Chinese population. BMC Genet 2010, 11(1):36

34. Parate PN, Wang D, Chew FT: Linkage Disequilibrium Pattern in Asthma Candidate Genes from 5q31-q33 in the Singapore Chinese Population. Ann Hum Genet 2010, 74:137-145.

35. Chiba Y, Kurotani R, Kusakabe T, Miura T, Link BW, Misawa M, Kimura S: Uteroglobin-related protein 1 expression suppresses allergic airway inflammation in mice. Am J Respir Crit Care Med 2006, 173(9):958-964.

36. Srisodsai A, Kurotani R, Chiba Y, Sheikh F, Young HA, Donnelly RP, Kimura S: Interleukin-10 induces uteroglobin-related protein (UGRP) 1 gene expression in lung epithelial cells through homeodomain transcription factor T/EBP/NKX2.1. Journal of Biological Chemistry 2004, 279(52):54358-54368.

37. Chiba Y, Srisodsai A, Supavilai P, Kimura S: Interleukin-5 reduces the expression of uteroglobin-related protein (UGRP) 1 gene in allergic airway inflammation. Immunology Letters 2005, 97(1):123-129.

38. Chiba Y, Kusakabe T, Kimura S: Decreased expression of uteroglobinrelated protein 1 in inflamed mouse airways is mediated by IL-9. American Journal of Physiology-Lung Cellular and Molecular Physiology 2004, 287(6):L1193-L1198.

39. de Burbure C, Pignatti P, Corradi M, Malerba M, Clippe A, Dumont X, Moscato G, Mutti A, Bernard A: Uteroglobin-related protein 1 and Clara cell protein in induced sputum of patients with asthma and rhinitis. Chest 2007, 131(1):172-179.

40. Alimonti A, Carracedo A, Clohessy JG, Trotman LC, Nardella C, Egia A, Salmena L, Sampieri K, Haveman WJ, Brogi E, et al: Subtle variations in Pten dose determine cancer susceptibility. Nature Genet 2010, 42(5):454-U136.

41. Dubois PCA, Trynka G, Franke L, Hunt KA, Romanos J, Curtotti A, Zhernakova A, Heap GAR, Adany R, Aromaa A, et al: Multiple common variants for celiac disease influencing immune gene expression. Nature Genet 2010, 42(4):295-U242

42. Kiesler P, Shakya A, Tantin D, Vercelli D: An allergy-associated polymorphism in a novel regulatory element enhances IL13 expression. Hum Mol Genet 2009, 18(23):4513-4520.

43. Hasegawa M, Nishiyama C, Nishiyama M, Akizawa Y, Mitsuishi K, Ito T, Kawada H, Furukawa S, Ra C, Okumura K, et al: A novel-66T/C polymorphism in Fc epsilon RI alpha-chain promoter affecting the transcription activity: Possible relationship to allergic diseases. I Immunol 2003, 171(4):1927-1933. 


\section{Pre-publication history}

The pre-publication history for this paper can be accessed here:

http://www.biomedcentral.com/1471-2350/12/39/prepub

doi:10.1186/1471-2350-12-39

Cite this article as: Andiappan et al:: Variation in Uteroglobin-Related

Protein 1 (UGRP1) gene is associated with Allergic Rhinitis in Singapore

Chinese. BMC Medical Genetics 2011 12:39.

Submit your next manuscript to BioMed Central and take full advantage of:

- Convenient online submission

- Thorough peer review

- No space constraints or color figure charges

- Immediate publication on acceptance

- Inclusion in PubMed, CAS, Scopus and Google Scholar

- Research which is freely available for redistribution

Submit your manuscript at 